\title{
Formação continuada em matemática de professores polivalentes - dois estudos sobre resolução de problemas aditivos
}

\author{
Mathematics for primary teachers and continuing education - two studies \\ about additives problem solving
}

Jutta Cornelia Reuwsaat Justo

jcrjusto@gmail.com

Beatriz Vargas Dorneles

bvdornel@terra.com.br

\begin{abstract}
Resumo
O presente artigo apresenta dois estudos que indicam a importância da formação continuada em matemática dos professores polivalentes e enfatiza o aprimoramento do processo de ensino e de aprendizagem. Para isso, apresenta uma investigação do desempenho de crianças na resolução de problemas aditivos e outra investigação com professores estudantes de Pedagogia na resolução de problemas aditivos. Verifica-se que os erros dos professores e dos alunos não se diferenciam muito, e que muitos professores apresentam dificuldades de compreensão dos conceitos que se prontificam a ensinar. Portanto, defende-se o indispensável conhecimento matemático do professor polivalente das séries iniciais, para um ensino eficiente e uma aprendizagem eficaz da resolução de problemas aditivos.
\end{abstract}

Palavras-chave: Educação Matemática. Formação continuada. Professores polivalentes. Problemas aditivos.

\begin{abstract}
This article presents two studies indicating the importance of continuing education of primary teachers in mathematics and emphasizes the improvement of teaching and learning. For this, presents a performance of children in additives problem solving and other research with pre-service teachers solving additives problems. It is found that the errors of the pre-service teachers do not differ much of the errors of children and that many teachers have difficulties in understanding the concepts that are willing to teach. Therefore, it argues the importance of comprehensive primary teacher's mathematical knowledge for an effective teaching and effective learning of additives problem solving.
\end{abstract}

Keywords: Mathematics Education. Continuing education. Primary teachers. Additives problems. 


\section{Introdução}

O presente artigo apresenta dois estudos que indicam a necessidade da formação continuada em matemática dos professores polivalentes, e enfatiza o aprimoramento do processo de ensino e de aprendizagem. Para isso, expõe uma investigação do desempenho de crianças na resolução de problemas aditivos e outra investigação com professores, estudantes de Pedagogia, na resolução dos mesmos. Estudos (Guimarães, 2010) apontam que os erros dos professores e de seus alunos não se diferenciam muito, além de existir professores com dificuldades de compreensão dos conceitos que se prontificam a ensinar. Nesse artigo, defende-se a importância do conhecimento matemático do professor polivalente das séries iniciais para um ensino eficiente e uma aprendizagem eficaz da resolução de problemas aditivos.

\section{Resolução de Problemas Aditivos}

A teoria dos campos conceituais, desenvolvida pelo professor e pesquisador francês Gérard Vergnaud, define um campo conceitual como o conjunto de situações cuja compreensão necessita do domínio de vários conceitos de naturezas diferentes. O campo conceitual aditivo é definido por Vergnaud (1990, 2003, 2009) como o conjunto de situações que pedem uma adição, uma subtração ou uma combinação das duas operações para serem resolvidas e, ao mesmo tempo, pelo conjunto dos conceitos e teoremas que permitem analisar essas situações como tarefas matemáticas.

Nunes e Bryant (2009) afirmam que enfocar a estrutura do problema e não as operações aritméticas utilizadas para resolver problemas, se tornou dominante na pesquisa em educação matemática nas últimas três décadas ou mais. Pesquisas na área têm aprofundado a resolução de problemas aditivos que vêm sendo classificados por diversos autores em categorias semânticas (CARPENTER; HIEBERT; MOSER, 1983; FAYOL, 1996; NESHER; GREENO; RILEY, 1982; NUNES; BRYANT, 1997; RILEY; GREENO; HELLER, 1983; VERGNAUD, 1990) e não mais pelas operações matemáticas que os resolvem.

Considerando, então, a categoria semântica, alguns estudos, que partiram dos indicados anteriormente, discriminaram 20 problemas aditivos classificados em quatro categorias de situações: transformação, combinação, comparação e igualação (BRANDÃo e SELVA, 1999; GARCÍA, JIMÉNEZ e HESS, 2006; JIMÉNEZ e GARCÍA, 2002; MIRANDA e GILLLARIO, 2001; ORRANTIA, 2006). Os problemas de transformação expressam uma ação 
direta sobre uma quantidade que lhe causa um aumento ou um decréscimo, isto é , uma situação inicial sofre mudança e transforma-se em uma situação final. Os problemas de comparação são aqueles em que quantidades são comparadas entre si. Os problemas que acarretam a comparação entre quantidades e uma mudança de uma dessas quantidades, para que uma igualdade seja estabelecida, são classificados como problemas de igualação. Por fim, os problemas de combinação implicam situações estáticas entre uma quantidade e suas partes.

Cada uma das quatro categorias identifica distintos tipos de problemas, dependendo de qual quantidade é desconhecida, ou seja, qual é o lugar da incógnita. Em função da posição da incógnita, os problemas possuem diferentes níveis de dificuldade, pois exigem raciocínios mais ou menos sofisticados. De acordo com o grau de dificuldade, em cada categoria encontramos situações classificadas em canônicas e não canônicas (GARCÍA; JIMÉNEZ; HESS, 2006) ou consistentes e inconsistentes (ORRANTIA, 2003, 2006).

Quadro 1 - Problemas matemáticos verbais canônicos e não-canônicos.

\begin{tabular}{|c|c|}
\hline \multicolumn{2}{|c|}{ PROBLEMAS MATEMÁTICOS VERBAIS } \\
\hline CANÔNICOS ou CONSISTENTES & NÃO CANÔNICOS ou INCONSISTENTES \\
\hline $\begin{array}{l}\text { A quantidade desconhecida é o resultado da operação. } \\
\text { (GARCÍA, JIMÉNEZ e HESS, 2006). } \\
\text { Podem ser resolvidos a partir de uma modelagem } \\
\text { direta em que o modelo da situação é construído } \\
\text { sequencialmente, tal como se apresenta no texto do } \\
\text { problema. O modelo de translação direta pode ser } \\
\text { funcional para resolver esse tipo de problema. } \\
\text { (ORRANTIA, 2003, 2006). } \\
\text { A quantidade desconhecida é o primeiro ou o segundo } \\
\text { termo da operação. (GARCÍA, JIMÉNEZ e HESS, } \\
\text { 2006). }\end{array}$ & $\begin{array}{l}\text { Apresentam uma situação aditiva que requer uma } \\
\text { subtração ou, ainda, uma situação subtrativa que } \\
\text { requer uma adição para encontrar a resposta. } \\
\text { (ORRANTIA, 2003, 2006). } \\
\text { São mais difíceis de resolver, necessitando um } \\
\text { conhecimento conceitual mais avançado do que os } \\
\text { consistentes ou canônicos. (GARCIA, JIMÉNEZ e } \\
\text { HESS, 2006; JIMÉNEZ e GARCÍA, 2002; } \\
\text { MIRANDA e GIL-LLARIO, 2001; ORRANTIA, } \\
\text { 2006; PESSOA, 2002; SÁ, 2002). }\end{array}$ \\
\hline
\end{tabular}

Fonte: Justo (2009).

Em cada uma das categorias semânticas dos problemas aditivos encontramos problemas canônicos e não canônicos. Essas variações são importantes porque exigem do professor e da criança diferentes raciocínios e estratégias de solução.

Nunes et al (2011) alertam para a necessidade de se trabalhar a relação inversa entre a adição e subtração, bem como a relação entre as quantidades em uma situação problema. Nos diferentes tipos de problemas aditivos, a relação entre as quantidades precisam ser compreendidas e não são de todo fundamentais as relações entre os números. Na pesquisa, os autores (NUNES et al, 2011) ressaltam que os cálculos numéricos dependem do entendimento 
das crianças acerca das relações entre números, também que os cálculos relacionais são sobre relações entre quantidades. Os dois tipos de cálculo são relativamente independentes um do outro e são provavelmente executados separadamente. Entretanto, são vinculados, porque nossas decisões sobre que tipo de cálculo fazer para resolver um problema, muitas vezes depende do nosso entendimento da relação entre as quantidades envolvidas na questão. Os pesquisadores concluíram que discutir a relação inversa entre adição e subtração é uma maneira efetiva de promover raciocínio relacional em problemas aditivos de transformação.

A complexidade da aprendizagem dos problemas aditivos encontra, ainda, outra problemática: a pouca divulgação e abrangência da abordagem da diversidade desse campo conceitual em livros didáticos, já que estes têm sido utilizados pelos professores como suporte de conhecimentos e de métodos de ensino.

A qualidade dos livros didáticos de Matemática ainda é duvidosa, em se tratando da aprendizagem de problemas aditivos, em termos tanto conceituais quanto metodológicos. Orrantia (2003) assegura que, em grande parte dos livros didáticos, há uma tendência generalizada de considerar os problemas aritméticos como um exercício das operações. Nisso, transparece uma concepção de que os alunos aprendem uma operação e depois resolvem uma série numerosa de problemas em que esta operação está implicada.

Duas pesquisas sobre os problemas aditivos encontrados em livros didáticos de Educação Primária na Espanha (ORRANTIA, GONZÁLEZ e VALENTE, 2005) e outra no Brasil (BRANDÃO; SELVA, 1999), verificaram que a frequência dos problemas considerados mais difíceis é praticamente nula. Os estudos evidenciaram as questões de transformação mais simples, ou seja, os de acréscimo e os de decréscimo com o resultado desconhecido, assim como os problemas de combinação são os mais frequentes nos livros usados nas escolas pelos alunos, ou no planejamento dos professores. Como esses problemas aditivos são os mais simples, exigindo um raciocínio mais elementar, eles pouco auxiliam no avanço da compreensão do campo conceitual das estruturas aditivas. Poder-se-ia perguntar, portanto, qual o motivo desse fato? Poderia ser o entendimento de que a resolução de problemas serve para o exercício das operações aritméticas que se está ensinando (ORRANTIA, GONZÁLEZ e VALENTE, 2005)? Ou seria um desconhecimento dos autores dos livros didáticos sobre as diferentes categorias que compõem esse campo conceitual? Acredita-se, que a questão da falta de um conhecimento maior ou mais aprofundado sobre o campo conceitual das estruturas aditivas, pelos educadores, talvez seja um dos aspectos relevantes para que as dificuldades de aprendizagem com a resolução de problemas aditivos se tornem tão acentuadas. 
O livro didático é um recurso muito usado no planejamento dos professores para suas aulas de resolução de problemas matemáticos. Como os livros pouco exploram a variedade de situações do campo conceitual aditivo, possivelmente as crianças tenham limitadas oportunidades de explorar diferentes problemas e, assim, ampliar o seu conhecimento na área. Dessa forma, pondera-se que um professor com um conhecimento mais aprofundado desse campo conceitual pode, ele próprio, pensar e criar variadas situações que compreendam a amplitude do campo aditivo.

Os estudos a seguir apresentam o desempenho de crianças e professores na resolução de problemas aditivos.

\section{ESTUDO 1}

\section{O desempenho dos alunos na resolução de problemas aditivos}

O primeiro estudo foi realizado em uma escola privada da região metropolitana de Porto Alegre/RS, que há quatro anos vinha estudando com os seus professores a diversidade dos problemas do campo aditivo. Verificamos o desempenho de 256 alunos de $1^{\mathrm{a}}$ a $4^{\mathrm{a}}$ série do Ensino Fundamental na resolução de problemas com estrutura aditiva. Para tanto, aplicamos dois testes, A e B, em dois momentos distintos, cada qual com a resolução de oito problemas aditivos, sendo seis problemas de transformação, seis de comparação, dois de composição e dois de igualação. As crianças realizaram os testes em horário escolar, acompanhadas por suas professoras, que as orientaram para que lessem e resolvessem os problemas individualmente. Apenas as professoras das $1^{\text {a }}$ séries poderiam ajudar na leitura do problema, caso alguma criança necessitasse.

O quadro 2 apresenta os problemas aditivos testados com um exemplo. 
Quadro 2 - Tipos de problemas aditivos nos testes A e B.

\begin{tabular}{|c|c|}
\hline Problema & ipo de Situação \\
\hline A1 & $\begin{array}{l}\text { Comparação: mais que - quantidade menor desconhecida } \\
\text { Luciana colheu } 34 \text { laranjas, ela colheu } 16 \text { a mais do que sua irmã Lúcia. Quantas laranjas Lúcia } \\
\text { colheu? }\end{array}$ \\
\hline A2 & $\begin{array}{l}\text { Comparação: menos que - quantidade menor desconhecida } \\
\text { Minha mãe tem } 42 \text { anos e minha tia tem } 14 \text { anos a menos do que ela. Qual a idade da minha tia? }\end{array}$ \\
\hline A3 & $\begin{array}{l}\text { Comparação: mais que; quantidade maior desconhecida } \\
\text { Roberto comprou uma lapiseira por } 12 \text { reais e um caderno que custou } 9 \text { reais a mais do que a } \\
\text { lapiseira. Quanto custou o caderno? }\end{array}$ \\
\hline A4 & $\begin{array}{l}\text { Comparação: menos que - quantidade maior desconhecida } \\
\text { Joel ganhou em uma partida } 43 \text { bolas de gude. Ele ganhou } 18 \text { a menos do que André. Quantas } \\
\text { bolas André ganhou? }\end{array}$ \\
\hline A5 & $\begin{array}{l}\text { Igualação: decréscimo na quantidade maior } \\
\mathrm{Na} 4^{a} \text { série há } 35 \text { cadeiras e } 26 \text { crianças. Quantas cadeiras eu preciso retirar da sala para ficar } \\
\text { com a mesma quantidade do que de crianças? }\end{array}$ \\
\hline A6 & $\begin{array}{l}\text { Igualação: acréscimo na quantidade menor } \\
\text { Na casa de Sérgio existem } 22 \text { árvores e na de Roberto existem 14. Quantas árvores Roberto } \\
\text { precisa plantar para ficar com a mesma quantidade de árvores que Sérgio? }\end{array}$ \\
\hline A7 & $\begin{array}{l}\text { Combinação: todo desconhecido } \\
\text { Alexandre tem } 8 \text { bombons e Leandro tem 14. Quantos bombons eles tem ao todo? }\end{array}$ \\
\hline A8 & $\begin{array}{l}\text { Combinação: parte desconhecida } \\
\text { Patrícia e Gabriel colecionam chaveiros. Eles têm, juntos, } 22 \text { chaveiros. Gabriel tem } 14 . \\
\text { Quantos chaveiros Patrícia tem? }\end{array}$ \\
\hline B1 & $\begin{array}{l}\text { Transformação: acréscimo - resultado desconhecido } \\
\text { Antônio tinha } 12 \text { figurinhas. Seu amigo Bruno lhe deu mais } 8 \text { figurinhas. Quantas figurinhas } \\
\text { Antônio tem agora? }\end{array}$ \\
\hline B2 & $\begin{array}{l}\text { Transformação: decréscimo - resultado desconhecido } \\
\text { Gláucia tinha } 14 \text { moedas. Ela deu } 3 \text { moedas para Mônica. Com quantas moedas ela ficou? }\end{array}$ \\
\hline B3 & $\begin{array}{l}\text { Transformação: acréscimo - transformação desconhecida } \\
\text { Sara tinha } 5 \text { chaveiros. Então, Cristina lhe deu mais alguns chaveiros. Agora Sara tem } 12 \\
\text { chaveiros. Quantos chaveiros Cristina deu para Sara? }\end{array}$ \\
\hline B4 & $\begin{array}{l}\text { Transformação: decréscimo - transformação desconhecida } \\
\text { Janaína tinha } 22 \text { lápis de cores. Na escola, ela deu alguns para suas amigas. Janaína agora tem } 8 \\
\text { lápis. Quantos lápis ela deu? }\end{array}$ \\
\hline B5 & $\begin{array}{l}\text { Transformação: acréscimo - início desconhecido } \\
\text { No meu aquário há alguns peixes. Então, eu coloquei mais } 4 \text { peixes. Agora eu tenho } 12 \text { peixes. } \\
\text { Quantos peixes eu tinha antes? }\end{array}$ \\
\hline B6 & $\begin{array}{l}\text { Transformação: decréscimo - início desconhecido } \\
\text { Em uma partida perdi } 12 \text { bolas de gude, ficando com } 21 \text {. Quantas bolas de gude eu tinha no } \\
\text { início do jogo? }\end{array}$ \\
\hline B7 & $\begin{array}{l}\text { Comparação: mais que - diferença desconhecida } \\
\text { Alice tinha } 12 \text { balas. Irene tinha } 5 \text { balas. Quantas balas Alice tem a mais que Irene? }\end{array}$ \\
\hline B8 & $\begin{array}{l}\text { Comparação: menos que - diferença desconhecida } \\
\text { Meu tio tem } 48 \text { anos e minha tia tem } 29 \text {. Quantos anos minha tia tem a menos que meu tio? }\end{array}$ \\
\hline
\end{tabular}

Fonte: Adaptado de Pessoa (2002).

Escolhemos os problemas referidos acima para que pudéssemos fazer uma comparação com a pesquisa realizada por Pessoa (2002), em Olinda, Pernambuco, com crianças de $4^{\text {a }}$ série do Ensino Fundamental e que apresenta os dados coletados de forma semelhante a nossa. 
O gráfico apresenta os dados relativos aos acertos em cada um dos tipos de problemas aplicados na escola privada.

Figura 1 - Acertos em cada série dos anos iniciais em cada problema aditivo na escola privada

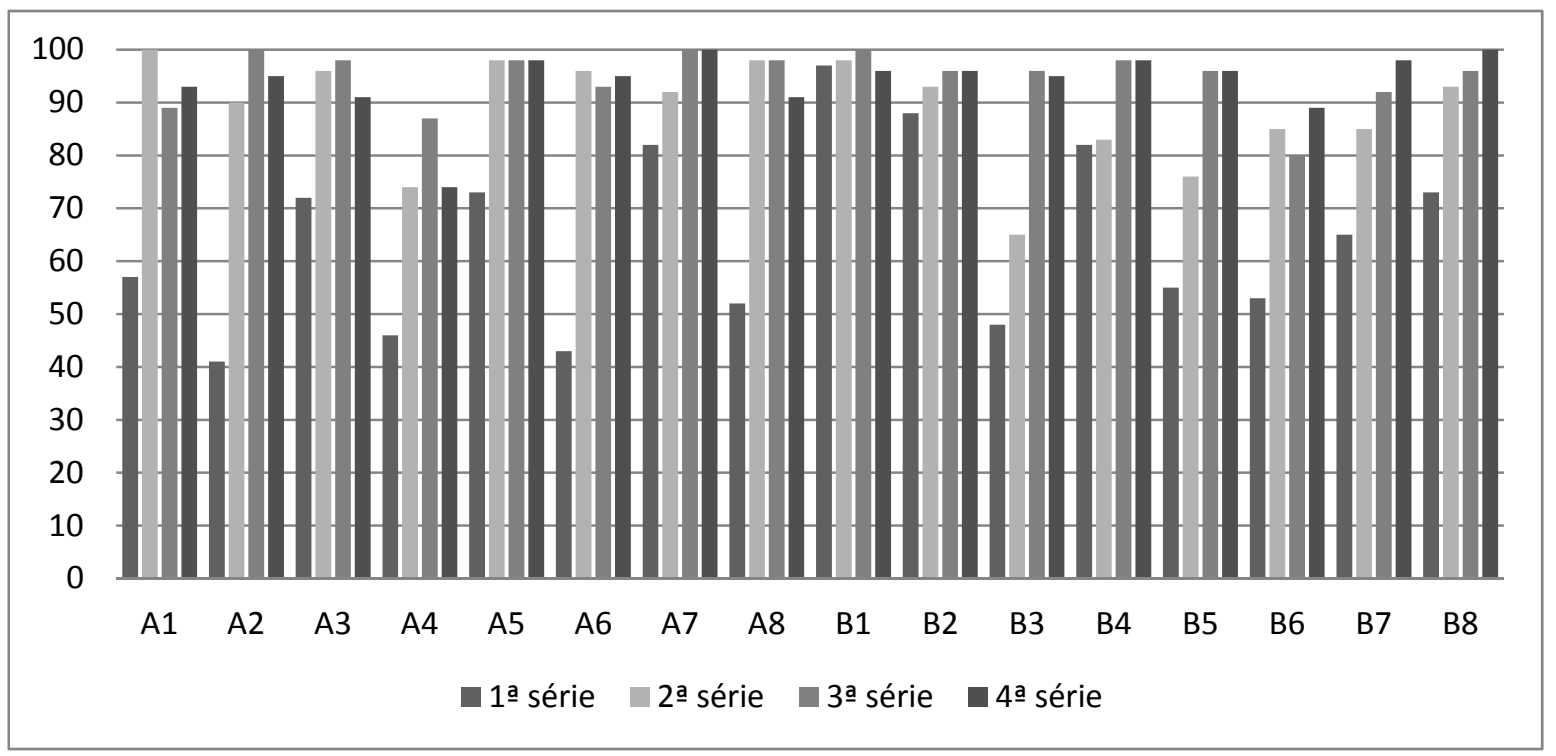

Fonte: JUSTO, 2007.

Verifica-se que os alunos da $3^{\mathrm{a}}$ e da $4^{\mathrm{a}}$ série apresentaram um índice de acertos superior a $90 \%$ em todos os problemas, com exceção da questão de transformação de decréscimo, com início desconhecido (B6) e do problema de comparação, com termo "menos que", quando a quantidade maior é desconhecida (A4): dois problemas não canônicos considerados mais difíceis de resolver. (GARCÍA; JIMÉNEZ; HESS, 2006; JIMÉNEZ; GARCÍA, 2002; JUSTO, 2009; JUSTO; DORNELES, 2010; MIRANDA; GIL-LLARIO, 2001; ORRANTIA, 2006; PESSOA, 2002; SÁ, 2002).

A $2^{\mathrm{a}}$ série também teve um índice de acertos acima de $90 \%$ em vários problemas, principalmente do teste $\mathrm{A}$, com exceção do problema não canônico de comparação: menos que - quantidade maior desconhecida (A4), assim como a $3^{\mathrm{a}}$ e a $4^{\mathrm{a}}$ série. No teste $\mathrm{B}$, os alunos da $2^{a}$ série obtiveram um índice superior a 90\% apenas em três problemas canônicos: B1, B2 e B8 - o que demonstra que há, nessa série, maior dificuldade em resolver problemas não canônicos de transformação, nos quais a transformação ou o início é desconhecido (B3, B4, B5, B6), e resolver o problema não canônico de comparação com o termo "mais que" em que a diferença é desconhecida (B7). 
A $1^{\text {a }}$ série apresentou um índice bem inferior de acertos, se comparado com as séries posteriores. A exceção ocorreu no problema de transformação de acréscimo com resultado desconhecido (B1), cujo índice de acertos foi 97\%. Ainda em torno de 80\% ficaram os problemas de transformação de decréscimo com resultado desconhecido (B2), com $88 \%$ de acertos; os de transformação de decréscimo com transformação desconhecida (B4); e os de combinação com o todo desconhecido (A7), ambos com $82 \%$ de acertos cada. Nunes et al (2005) também verificaram um índice superior a 80\% na resolução desses problemas desde a $1^{a}$ série, na pesquisa com alunos de escolas públicas no estado de São Paulo, Brasil. Os pesquisadores justificam esse índice de acertos nesse tipo de problema, afirmando que são as situações mais simples que exigem o raciocínio aditivo. As questões com mais acertos nessa série são todos canônicos, ou seja, de mais fácil resolução.

Na figura 2 são apresentados acertos dos alunos de $4^{\text {a }}$ série nos problemas aditivos em uma escola pública (PESSOA, 2002) e outra escola privada que fizeram parte da investigação. Os resultados dessa comparação inspiraram a pesquisa de doutorado da primeira autora. (JUSTO, 2009).

Figura 2 - Comparativo do desempenho em problemas aditivos de alunos de $4^{\mathrm{a}}$ série de escolas públicas (PESSOA, 2002) e privada.



Fonte: JUSTO (2007).

Sabe-se, que as diferenças de desempenho dos estudantes de escolas púbicas e privadas encontram explicações na ordem de fatores intra e extraescolares (BROOKE; SOARES, 
2008). Para efeito do estudo realizado, consideramos que, entre as possíveis explicações para a diferença no desempenho entre as escolas, o melhor desempenho das crianças da escola privada pode estar vinculado à existência de um currículo diferenciado, no qual uma variedade maior de problemas aditivos são resolvidos pelos alunos dessa escola, em virtude de seus professores já terem participado de formação continuada na escola em que se tratou a diversidade dos problemas aditivos. Além disso, o currículo de Matemática dessa escola abrange o ensino de diferentes categorias de problemas envolvidos no campo conceitual aditivo.

Outro aspecto importante é a comparação entre os resultados dos alunos da $4^{\mathrm{a}}$ série da escola pública (PESSOA, 2002) e o desempenho dos alunos da $1^{\mathrm{a}}$ série da escola privada, que estão expostos na figura 3. Essa comparação credita maior confiança na tese de que um programa de ensino e um programa de formação continuada, compreendendo o ensino da diversidade dos problemas aditivos, já desde a $1^{\mathrm{a}}$ série, pode auxiliar na evolução desse conhecimento. Os dados no gráfico comprovam:

Figura 3 - Desempenho de alunos de $4^{\text {a }}$ série de escola pública (PESSOA, 2002) e de alunos de $1^{\text {a }}$ série de escola privada (Justo, 2007) em problemas aditivos.



Fonte: JUSTO (2007).

Verifica-se que o desempenho dos dois grupos de alunos é muito próximo. Os alunos da $4^{\mathrm{a}}$ série da escola pública apresentaram um desempenho melhor em sete dos dezesseis problemas aditivos. O melhor resultado dos alunos da $4^{\mathrm{a}}$ série da escola pública foi em problemas de 
transformação: decréscimo - início desconhecido (B6); Comparação: menos que - quantidade menor desconhecida (A2); Comparação: mais que - quantidade maior desconhecida (A3); Igualação: acréscimo na quantidade menor (A6); Combinação: parte desconhecida (A8); Comparação: menos que - quantidade maior desconhecida (A4) e Comparação: mais que quantidade menor desconhecida (A1). Pode-se verificar que os alunos da $4^{\mathrm{a}}$ série se saíram melhor do que os da $1^{\mathrm{a}}$ série, em problemas não canônicos que foram considerados como mais difíceis (GARCÍA; JIMÉNEZ; HESS, 2006; JIMÉNEZ; GARCÍA, 2002; JUSTO, 2009; JUSTO; DORNELES, 2010; MIRANDA; GIL-LLARIO, 2001; ORRANTIA, 2006; PESSOA, 2002; SÁ, 2002), sendo exceção os problemas canônicos de Comparação: menos que quantidade menor desconhecida (A2) e Comparação: mais que - quantidade maior desconhecida (A3).

Talvez, os professores da escola pública, pesquisada por Pessoa (2002), pudessem ter pouco de conhecimento sobre a diversidade e amplitude do campo conceitual aditivo. Essa questão, aliada à limitação dos livros didáticos quanto a variedade de problemas aditivos (ORRANTIA; GONZÁLEZ; VICENTE, 2005; BRANDÃO; SELVA, 1999), pode influenciar no pequeno avanço da aprendizagem do campo conceitual aditivo.

O próximo estudo enfoca o conhecimento matemático do professor acerca dos problemas aditivos.

\section{ESTUDO 2}

\section{O desempenho dos professores na resolução de problemas aditivos}

A comparação entre as duas escolas abriu espaço para o desafio de investigar o conhecimento de professores no campo conceitual aditivo. Outra razão para essa nova investigação surgiu com o início da correção dos testes realizados pelos alunos do segundo estudo. Na ocasião, foram encontrados, junto aos testes da $3^{\mathrm{a}}$ série, um que havia sido resolvido por uma das professoras da escola privada. Ficou claro que ela havia errado um dos problemas: o de transformação com situação de decréscimo e início desconhecido (B6). Justamente o problema que apresentou maior índice de erros na $3^{\mathrm{a}}$ e na $4^{\mathrm{a}}$ série. A fim de buscar solução para o caso, decidiu-se ampliar a investigação, incluindo professores. 
O teste foi aplicado em alunas de duas turmas do curso de Pedagogia da Universidade Luterana do Brasil (ULBRA), em Canoas/RS, também, em alunas de uma turma do curso de Pedagogia da Universidade Federal do Rio Grande do Sul (UFRGS) ${ }^{1}$. Acredita-se que, esta aplicação com alunas do curso de Pedagogia, pôde fornecer elementos necessários para identificar o conhecimento matemático do professor de anos iniciais, na resolução dos diferentes problemas aditivo, bem como as principais dificuldades para ensiná-lo, pois muitas alunas do curso de Pedagogia já são ou serão professoras dos anos iniciais do Ensino Fundamental futuramente ${ }^{2}$.

O teste aplicado com alunas/professoras do curso de Pedagogia nas duas universidades envolveu seis problemas de transformação, seis de igualação, seis de comparação e dois de combinação, totalizando 20 problemas aditivos. Quatro problemas de igualação que compõem esse teste ainda não havia sido testado com as crianças dos anos iniciais do Ensino Fundamental. Essa investigação ocorreu posteriormente. (JUSTO, 2009).

As alunas/professoras do curso de Pedagogia resolveram todos os 20 problemas em um único momento. Elas o fizeram individualmente, escrevendo o cálculo e a resposta encontrada em uma folha branca, em anexo, identificando o número do problema resolvido.

No teste, os problemas foram organizados na sequência apresentada na Tabela 5.

Tabela 5 - Sequência de problemas aditivos resolvidos por um grupo de alunas/professoras de dois cursos de Pedagogia, de duas universidades do sul do Brasil.

\begin{tabular}{|c|l|}
\hline PROBLEMA & TIPO \\
\hline 1 & $\begin{array}{l}\text { Transformação: acréscimo - resultado desconhecido } \\
\text { Antônio tinha 12 figurinhas. Seu amigo Bruno lhe deu mais 8 figurinhas. Quantas } \\
\text { figurinhas Antônio tem agora? }\end{array}$ \\
\hline 2 & $\begin{array}{l}\text { Transformação: decréscimo - resultado desconhecido } \\
\text { Gláucia tinha 14 moedas. Ela deu } 3 \text { moedas para Mônica. Com quantas moedas } \\
\text { ela ficou? }\end{array}$ \\
\hline 3 & $\begin{array}{l}\text { Transformação: acréscimo - transformação desconhecida } \\
\text { Sara tinha 5 chaveiros. Então, Cristina lhe deu mais alguns chaveiros. Agora Sara } \\
\text { tem 12 chaveiros. Quantos chaveiros Cristina deu para Sara? }\end{array}$ \\
\hline 4 & $\begin{array}{l}\text { Transformação: decréscimo - transformação desconhecida } \\
\text { Janaína tinha 22 lápis de cores. Na escola, ela deu alguns para suas amigas. } \\
\text { Janaína agora tem 8 lápis. Quantos lápis ela deu? }\end{array}$ \\
\hline 5 & $\begin{array}{l}\text { Transformação: acréscimo - início desconhecido } \\
\text { No meu aquário tem alguns peixes. Então, eu coloquei mais 4 peixes. Agora eu } \\
\text { tenho 12 peixes. Quantos peixes eu tinha antes? }\end{array}$ \\
\hline
\end{tabular}

${ }^{1}$ As duas universidades localizam-se próximo à escola privada pesquisada, na região metropolitana de Porto Alegre/RS, região sul do Brasil.

${ }^{2}$ Desse ponto em diante, ao nos referirmos às alunas do Curso de Pedagogia das duas Universidades, usaremos a expressão "alunas/professoras", para que se evidencie a identidade de professor desses sujeitos. 


\begin{tabular}{|c|c|}
\hline 6 & $\begin{array}{l}\text { Transformação: decréscimo - início desconhecido } \\
\text { Em uma partida perdi } 12 \text { bolas de gude, ficando com 21. Quantas bolas de gude } \\
\text { eu tinha no início do jogo? }\end{array}$ \\
\hline 7 & $\begin{array}{l}\text { Comparação: termo a mais - diferença desconhecida } \\
\text { Alice tinha } 12 \text { balas. Irene tinha } 5 \text { balas. Quantas balas Alice tem a mais que } \\
\text { Irene? }\end{array}$ \\
\hline 8 & $\begin{array}{l}\text { Comparação: termo a menos - diferença desconhecida } \\
\text { Meu tio tem } 48 \text { anos e minha tia tem } 29 \text {. Quantos anos minha tia tem a menos que } \\
\text { meu tio? }\end{array}$ \\
\hline 9 & $\begin{array}{l}\text { Comparação: termo a mais - quantidade menor desconhecida } \\
\text { Luciana colheu } 34 \text { laranjas, ela colheu } 16 \text { a mais do que sua irmã Lúcia. Quantas } \\
\text { laranjas Lúcia colheu? }\end{array}$ \\
\hline 10 & $\begin{array}{l}\text { Comparação: termo a menos - quantidade menor desconhecida } \\
\text { Minha mãe tem } 42 \text { anos e minha tia tem } 14 \text { anos a menos do que ela. Qual a idade } \\
\text { da minha tia? }\end{array}$ \\
\hline 11 & $\begin{array}{l}\text { Comparação: termo a mais - quantidade maior desconhecida } \\
\text { Roberto comprou uma lapiseira por } 12 \text { reais e um caderno que custou } 9 \text { reais a } \\
\text { mais que a lapiseira. Quanto custou o caderno? }\end{array}$ \\
\hline 12 & $\begin{array}{l}\text { Comparação: termo a menos - quantidade maior desconhecida } \\
\text { Joel ganhou em uma partida } 43 \text { bolas de gudes. Ele ganhou } 18 \text { a menos do que } \\
\text { André. Quantas bolas André ganhou? }\end{array}$ \\
\hline 13 & $\begin{array}{l}\text { Igualação: decréscimo na quantidade maior } \\
\mathrm{Na} 4^{\mathrm{a}} \text { série tem } 35 \text { cadeiras e } 26 \text { crianças. Quantas cadeiras eu preciso retirar da } \\
\text { sala para ficar com a mesma quantidade do que de crianças? }\end{array}$ \\
\hline 14 & $\begin{array}{l}\text { Igualação: acréscimo na quantidade menor } \\
\text { Na casa de Adalberto existem } 22 \text { árvores e na de Roberto existem 14. Quantas } \\
\text { árvores Roberto precisa plantar para ficar com a mesma quantidade de árvores } \\
\text { que Adalberto? }\end{array}$ \\
\hline 15 & $\begin{array}{l}\text { Combinação: todo desconhecido } \\
\text { Alexandre tem } 8 \text { bombons e Leandro tem } 14 \text {. Quantos bombons eles têm ao todo? }\end{array}$ \\
\hline 16 & $\begin{array}{l}\text { Combinação: parte desconhecida } \\
\text { Patrícia e Gabriel colecionam chaveiros. Eles têm juntos } 22 \text { chaveiros. Gabriel } \\
\text { tem 14. Quantos chaveiros Patrícia tem? }\end{array}$ \\
\hline 17 & $\begin{array}{l}\text { Igualação: acréscimo - "fazer o valor conhecido igualar" } \\
\text { Marcelo tem } 15 \text { reais. Se a sua mãe lhe der mais } 9 \text {, ele terá a mesma quantia que } \\
\text { Davi. Quantos reais tem Davi? }\end{array}$ \\
\hline 18 & $\begin{array}{l}\text { Igualação: decréscimo - "fazer o valor conhecido igualar" } \\
\text { Neco tem } 13 \text { carrinhos. Se ele der } 9 \text { dos seus carrinhos, ele terá o mesmo número } \\
\text { de carrinhos que Zeca. Quantos carrinhos tem Zeca? }\end{array}$ \\
\hline 19 & $\begin{array}{l}\text { Igualação: acréscimo - "fazer o valor desconhecido igualar" } \\
\text { Meu vestido tem } 12 \text { botões. Se o vestido de minha irmã tivesse } 5 \text { botões a mais, } \\
\text { ele teria o mesmo número de botões que o meu. Quantos botões tem o vestido de } \\
\text { minha irmã? }\end{array}$ \\
\hline 20 & $\begin{array}{l}\text { Igualação: decréscimo - "fazer o valor desconhecido igualar" } \\
\text { No ônibus que vai para Porto Alegre há } 17 \text { pessoas; se } 6 \text { pessoas descerem do } \\
\text { ônibus que vai a Feliz, haverá o mesmo número de pessoas nele como no ônibus } \\
\text { que vai para Porto Alegre. Quantas pessoas estão no ônibus que vai a Feliz? }\end{array}$ \\
\hline
\end{tabular}

Após realizada a correção, foi considerada a resolução certa quando a operação empregada para resolver o problema era adequada, ou seja, se o raciocínio efetuado levava à solução do 
problema. O resultado do cálculo efetuado, se correto ou não, não foi considerado relevante para essa investigação.

Os testes foram aplicados em 41 alunas/professoras da disciplina de Matemática Aplicada para a Educação Infantil, Anos Iniciais do curso de Pedagogia da ULBRA e com 35 alunas/professoras do curso de Pedagogia da UFRGS, totalizando 76 alunas/professoras.

A figura 4 mostra os problemas em que o total de alunas/professoras das duas universidades investigadas apresentaram erros e seu respectivo percentual:

Figura 4 - Índice de erros realizados por alunas/professoras da ULBRA/Canoas e da UFRGS em problemas aditivos.

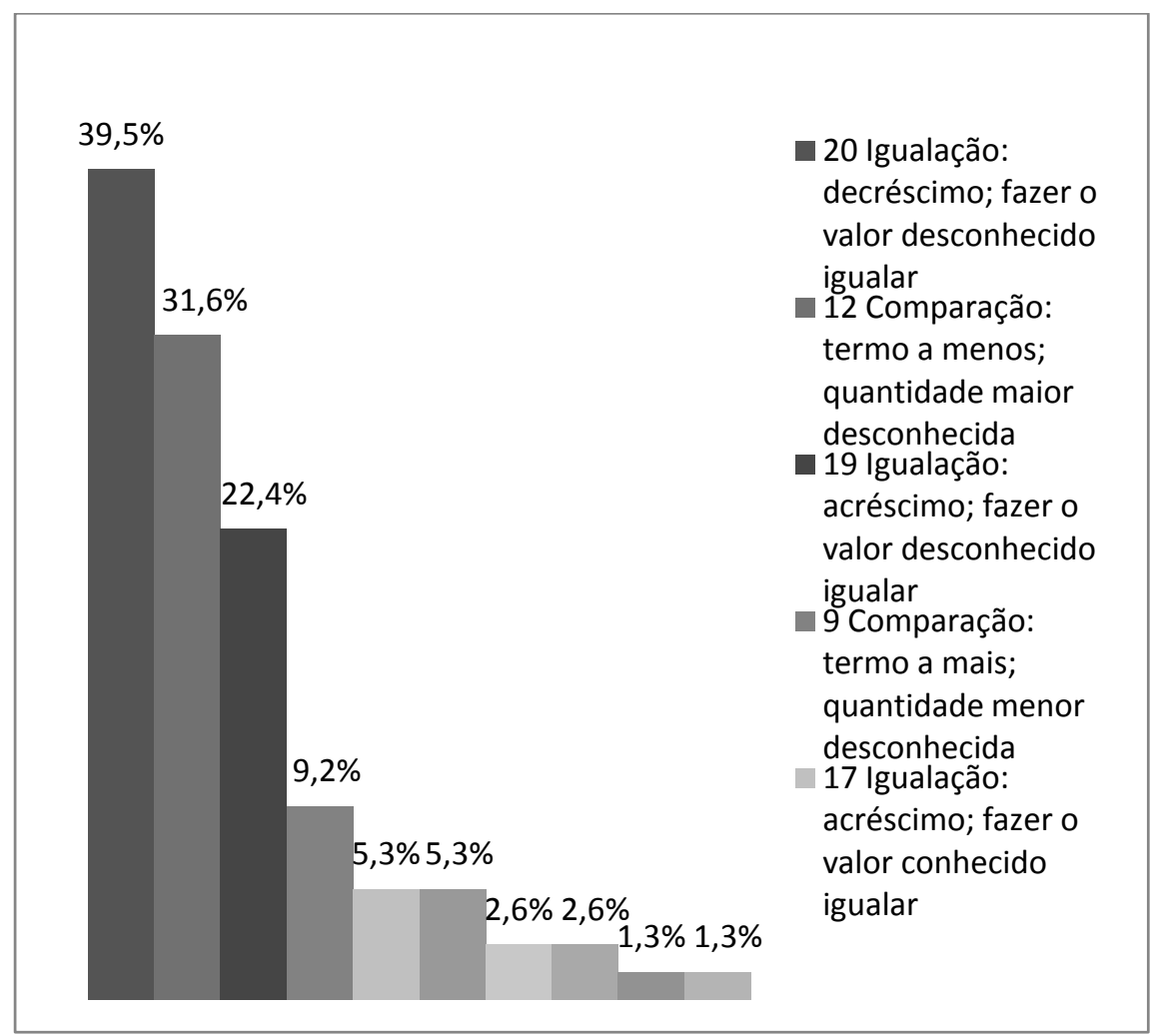

Fonte: JUSTO (2007).

Os quatro problemas que apresentaram maior dificuldade para as alunas/professoras foram problemas não canônicos de igualação e de comparação. As pesquisas que tratam dos 20 tipos de problemas aditivos, em bloco, evidenciam que esses são os mais difíceis para as crianças, sugerindo que a sua aprendizagem seja mais tardia (GARCÍA; JIMÉNEZ; HESS, 2006; JIMÉNEZ; GARCÍA, 2002; JUSTO, 2009; JUSTO; DORNELES, 2010; MIRANDA; GILLLARIO, 2001; ORRANTIA, 2006; PESSOA, 2002; SÁ, 2002). 
As maiores dificuldades apresentadas pelas alunas/professoras da Pedagogia evidenciaram-se nos problemas de igualação, em situação de decréscimo, quando se deve fazer o valor desconhecido igualar, tais como: Antônio tem 34 bolinhas de gude. Se Rafael tivesse 12 bolinhas a menos, ele teria a mesma quantidade que o Antônio. Quantas bolinhas têm o Rafael? O problema de comparação que as alunas/professoras mais erraram foi o mesmo em que as crianças apresentaram maior dificuldade: o problema de comparação: menos que quantidade maior desconhecida. Por exemplo: Joel ganhou em uma partida 43 bolas de gude. Ele ganhou 18 a menos do que André. Quantas bolas André ganhou?

Com isso, pode-se afirmar, em consonância com Guimarães (2010), que as dificuldades dos professores se assemelham às dificuldades enfrentadas pelas crianças na resolução de problemas matemáticos aditivos. Assim, os resultados do desempenho das crianças e das estudantes de Pedagogia, levam a pensar na elaboração de um programa de ensino de problemas aditivos que prevê, também, a formação dos professores para implementá-lo. $\mathrm{O}$ programa de ensino deveria privilegiar o cálculo relacional envolvido nos diferentes problemas aditivos. (JUSTO, 2009). Tal programa justificou-se, pois, em tese, todas as crianças podem aprender, independentemente de estudar em uma escola pública ou privada, ou ainda da condição econômico-social em que se encontram. O que as crianças precisam é de uma boa escola e de um bom professor, que tenha conhecimento de conteúdo, conhecimento didático do conteúdo e conhecimento sobre como seu aluno aprende. (JUSTO, 2009; JUSTO; DORNELES, 2010).

Curi $(2004,2008)$ defende que o conhecimento matemático do professor polivalente deve ser relacionado a conceitos, a procedimentos e a atitudes em relação à matemática. Ele precisa saber os significados das operações, suas propriedades, a técnica operatória e aplicá-las ao resolver problemas. É necessário que o professor desenvolva ou aprimore suas capacidades de resolver problemas, argumentar, raciocinar e comunicar-se matematicamente. Além disso, ele precisa estimular uma atitude positiva frente à Matemática, para que possa ter confiança em sua capacidade de ensinar e aprender, influenciando, dessa forma, também a aprendizagem de seus alunos.

Os conhecimentos necessários ao professor - o conhecimento do conteúdo matemático e o conhecimento didático do conteúdo matemático - foram intensamente estudados pelo norteamericano Lee Shulman, e servem de referência na maioria dos estudos sobre o conhecimento do professor para a totalidade dos pesquisadores consultados para este trabalho. Shulman (1987) explicita várias categorias dessa base de conhecimento (conhecimento de conteúdo 
específico, conhecimento pedagógico geral, conhecimento do currículo, conhecimento pedagógico do conteúdo, conhecimento dos alunos e de suas características, conhecimentos dos contextos educacionais, conhecimento dos fins, propósitos e valores educacionais) que podem ser agrupadas em: conhecimento do conteúdo específico, conhecimento pedagógico geral e conhecimento pedagógico do conteúdo. Esse domínio é fundamental para que o professor tenha autonomia intelectual para produzir e planejar as situações didáticas que irá propor aos seus alunos e, assim, percebe-se a prática reflexiva como um caminho promissor na formação de professores.

Compreende-se, que as capacidades desejáveis ao professor, até aqui discutidas, pressupõem uma formação permanente, ou seja, o professor deveria estar aprendendo sempre em seu ambiente de trabalho para compor uma equipe de professores capazes de garantir a aprendizagem do aluno, mediante uma atuação competente e compromissada. Tais momentos sugerem uma reflexão coletiva, onde cada um é responsável por dialogar com o outro e consigo mesmo, provocando e desmobilizando, desconstruindo e reconstruindo conceitos, colaborativamente, reflexivamente, fazendo o princípio recair na reflexão sobre a prática. Curi (2008, p. 432) afirma que uma melhoria nos conhecimentos matemáticos, didáticos e curriculares ocorre "quando professores participam de processos de formação que possibilitam reflexões, relações entre teoria, prática e pesquisa e proporcionam análises e planejamento de atividades em que esses conhecimentos são utilizados em sua prática no ensino."

Sendo os professores da Educação Infantil e dos anos iniciais do Ensino Fundamental as primeiras pessoas que formalmente ensinam para as crianças as primeiras noções matemáticas, é imprescindível que estes sejam profissionais qualificados e que tenham uma relação positiva com a disciplina, para que possam auxiliar na forte constituição de uma aproximação satisfatória das crianças com a matemática e no desenvolvimento dos conceitos matemáticos de seus alunos. Parte-se do pressuposto de que conhecer matemática para auxiliar o aluno a pensar matematicamente, e encontrar caminhos para chegar a determinadas soluções, é tarefa do professor preparado para ser um educador matemático.

Uma preocupação quanto à formação desse professor reside no fato de que muitos dos estudantes de Pedagogia e dos professores polivalentes não tem uma relação positiva com a matemática, sendo assim necessário que eles construam conhecimentos e sentimentos de confiança em relação ao conteúdo matemático, principalmente em sua capacidade de aprender e ensinar matemática. Como já disse Guiomar Namo de Mello, "ninguém promove a 
aprendizagem de conteúdos que não domina nem a constituição de significados que não possui ou a autonomia que não teve oportunidade de construir". (MELLO, 2001, p. 156). Por isso, a formação inicial e continuada de professores polivalentes tem a sua relevância, para que o professor desenvolva e aprimore a sua capacidade de ensinar e as crianças construam as suas aprendizagens com mais eficácia. Assim como Lopes (2005), pressupõe-se que esse professor seja responsável e competente, que detenha conhecimento próprio e capacidade reflexiva e de ação quanto a sua prática e seu desenvolvimento profissional.

\section{Conclusões}

Os dois estudos apresentados em conjunto e a breve reflexão sobre o conhecimento matemático e a formação continuada levam à algumas conclusões.

Os erros apresentados pelos alunos e professores na resolução de problemas aditivos são semelhantes nos estudos apresentados. Os problemas mais difíceis para os dois grupos pertencem às categorias de comparação e de igualação. $\mathrm{O}$ fato de as alunas/professoras, em formação, cometerem os mesmos erros que as crianças que elas ensinarão, faz com que maior atenção esteja voltada para a formação inicial desses professores. Além disso, aponta para a formação continuada em serviço como trabalho essencial na melhoria do ensino e da aprendizagem.

A formação continuada que o presente estudo defende, abarca um pouco de cada uma dessas concepções: a formação baseada na reflexão sobre a prática, buscando a transformação da prática de cada professor em colaboração com seus pares, intensificando a pesquisa no locus escolar. Acredita-se em uma formação que contemple, além de palestras, cursos e oficinas, o intercâmbio de ideias entre professores de diferentes escolas e níveis, observações de aulas e reflexões com seus pares, planejamentos em grupos e individuais com um supervisor educacional. Ou seja, uma formação continuada que tome como ponto de partida e de chegada os saberes docentes: conhecimento sobre o conteúdo matemático, conhecimento sobre como seu aluno aprende matemática e conhecimento metodológico.

Pressupondo, assim, que a formação inicial e continuada precisa considerar a atualização do conhecimento matemático do professor polivalente, no contexto da prática docente, ou seja, no locus escolar, onde as situações reais de sala de aula possam servir como ponto de partida para a reflexão do professor sobre a sua prática, bem como para a melhoria da aprendizagem. 
Um currículo de matemática, ao pensar nos conteúdos a serem ensinados, os pense a partir da inclusão social dos estudantes. Dessa forma, considerar a possibilidade de que todos devem e podem aprender matemática. Nessa mesma perspectiva, o professor polivalente também precisa acreditar que pode aprender e ensinar matemática. O professor polivalente em formação precisa modificar as suas crenças e sentimentos ruins em relação à matemática, rompendo com saberes adquiridos durante a sua trajetória estudantil. Um professor que gosta e conhece o objeto de ensino, mais facilmente ensina, e o seu aluno, possivelmente, aprende mais.

\section{Referências}

BRANDÃO, A. C.; SELVA, A. C. V. O livro didático na educação infantil: reflexão versus repetição na resolução de problemas matemáticos. Educação e Pesquisa, São Paulo, v. 25, n. 2, p. 69-83, jul./dez. 1999.

BROOKE, N.; SOARES, J. F. (Orgs.) Pesquisa em eficácia escolar: origem e trajetórias. Belo Horizonte: Editora UFMG, 2008.

CARPENTER, T. P.; HIEBERT, J.; MOSER, J. M. The effect of instruction on children's solutions of addition and subtraction word problems. Educational Studies in Mathematics, Boston, v. 14, n. 1, pp. 55-72, 1983.

CURI, Edda. Formação de Professores Polivalentes: uma análise de conhecimentos para ensinar matemática e de crenças e atitudes que interferem na constituição desses conhecimentos. Tese (Doutorado em Educação Matemática) - Pontifícia Universidade Católica de São Paulo, 2004.

CURI, Edda. A formação matemática dos professores das séries iniciais. Anais [do] II Fórum Baiano das Licenciaturas em Matemática: (Re)definindo os rumos para a formação de professores de Matemática na Bahia, Barreiras, BA, 21 a 23 de novembro de 2008. Barreiras, BA: Sociedade Brasileira de Educação Matemática / Regional Bahia, 2008.

FAYOL, Michel. A criança e o número: da contagem à resolução de problemas. Porto Alegre: Artes Médicas, 1996.

GARCÍA, A. I.; JIMÉNEZ, J. E.; HESS, S. Solving Arithmetic Word Problems: An analysis of classification as a function of difficulty in children with and without arithmetic LD. Journal of Learning Disabilities, v. 39, n. 3, may/june 2006, pp. 270-281.

JIMÉNEZ, J. E.; GARCÍA, A. I. Strategy choice in solving arithmetic word problems: are there differences between students with learning disabilities, G-V poor performance and typical achievement students? Learning Disability Quarterly, 25, p. 113-122, Spring 2002. 
JUSTO, Jutta C. R. Aprendizagem de problemas do campo aditivo. Projeto de Tese (Doutorado em Educação), Faculdade de Educação, Universidade Federal do Rio Grande do Sul. Porto Alegre: UFRGS, 2007.

JUSTO, Jutta C. R. Resolução de problemas matemáticos aditivos: possibilidades da ação docente. Tese (Doutorado em Educação), Faculdade de Educação, Universidade Federal do Rio Grande do Sul. Porto Alegre: UFRGS, 2009.

JUSTO, Jutta C. R.; DORNELES, Beatriz V. Resolução de Problemas Matemáticos Aditivos: possibilidades da ação docente. Acta Scientiae: Revista de Ensino de Ciências e Matemática, Universidade Luterana do Brasil, Canoas, Brasil, v. 12, n. 2 - jul./dez. 2010, pp. 106-124.

GUIMARÃES, Gilda Lisbôa. Formação de professores: trabalhando com gráficos e tabelas na educação infantil. Revista Iberoamericana de Educación Matemática, Marzo de 2010, n. 21, pp 87-101.

LOPES, Celi A. E. Um Grupo Colaborativo de Educadoras de Infância e suas Relações com a Estocástica. In: FIORENTINI, D.; NACARATO, A.M. (orgs). Cultura, formação e desenvolvimento profissional de professores que ensinam matemática. São Paulo: Musa Editora; Campinas, SP: GEPFPM-PRAPEM-FE/UNICAMP, 2005.

MELLO, Guiomar Namo de. Formação inicial de professores para a educação básica: uma (re)visão radical. Revista Iberoamericana de Educación. Nº 25 (2001), pp. 147-174.

MIRANDA, A.; GIL-LLARIO, M. D. Las Dificultades de Aprendizaje en las Matemáticas: concepto, manifestaciones y procedimientos de manejo. Revista de Neurologia Clínica, 2(1), p. 55-71, 2001.

NACARATO, A. M.; MENGAli, B. L. S.; PASSOS, C. L. B. A Matemática nos Anos Iniciais do Ensino Fundamental: tecendo fios do ensinar e do aprender. Belo Horizonte: Atêntica Editora, 2009.

NESHER, P.; GREENO, J. G.; RILEY, M. S. The development of semantic categories for addition and subtraction. Educational Studies in Mathematics, Boston, v. 13, n.4, pp. 373394, nov-dec. 1982.

NUNES, T.; BRYANT, P. Crianças fazendo matemática. Porto Alegre: Artmed, 1997.

NUNES, T.; BRYANT, P. Paper 4: Understanding relations and their graphical representation. Key understandings in mathematics learning. Nuffield Foundation, London, 2009. Disponível em: www.nuffieldfoundation.org.

NUNES, T.; BRYANT, P.; EVANS, D.; BELL, D.; BARROS, R. Teaching children how to include the inversion principle in their reasoning about quantitative relations. Educational Studies of Mathematics, Online First ${ }^{\mathrm{TM}}$, 17 March 2011. Disponível em: http://www.springerlink.com/content/0013-1954.

NUNES, T.; CAMPOS, T. M. M.; MAGINA, S.; BRYANT, P. Educação Matemática: números e operações numéricas. São Paulo: Cortez, 2005. 
ORRANTIA, Josetxu. El rol del conocimiento conceptual en la resolución de problemas aritméticos con estructura aditiva. Infancia y Aprendizaje, vol. 26(4), p. 451-468, 2003.

ORRANTIA, Josetxu. Dificultades en el Aprendizaje de las Matemáticas: una perspectiva evolutiva. Revista de Psicopedagogia, vol 23(71), p. 158-180, 2006.

ORRANTIA, J.; GONZÁLEZ, L.B.; VICENTE, S. Un análisis de los problemas aritméticos en los libros de texto de Educación Primaria. Infancia y Aprendizaje, vol. 28(4), pp 429$451,2005$.

PESSOA, C. A. S. Interação Social: uma análise do seu papel na superação de dificuldades de resolução de problemas aditivos. In: Anais da 25 ANPED, set/out, 2002. Disponível em: http://www.anped.org.br/25 Acesso em 09 jan. 2004.

RILEY, M. S.; GREENO, J. G.; HELLER, J. I. Development of children's problem-solving ability in arithmetic. In: GINSBURG, H. (Ed.). The Development of Mathematical Thinkin. New York: Academic Press, 1983.

SÁ, Pedro F. Porque alguns problemas aditivos são mais difíceis que outros? In: Anais do V Encontro Pernambucano de Educação Matemática, out, 2002. Disponível em: http://www.dmat.ufpe.br/ mro/extensao/v_epem/anais. Acesso em 09 jan. 2004.

SHULMAN, L. S. Knowledge and teaching: foundations of the new reform. Harvard Educational Review, 57 (1), 1987, p. 1-22. Disponível em: http://ci.unlv.edu/files/Week3_Shulman_Knowledge_Teaching.pdf.

TARDIF, Maurice. Saberes docentes e formação profissional. Tradução: Francisco Pereira. $4^{\text {a }}$ ed. Petrópolis: Vozes, 2004.

VERGNAUD, Gérard. TheTheory of Conceptual Fields. Human Development; n. 52, pp. 83-94, 2009.

VERGNAUD, Gérard. A gênese dos campos conceituais. In: GROSSI, E.P. (Org.). Por que ainda há quem não aprende? A teoria. Petrópolis, RJ: Vozes, 2003.

VERGNAUD, Gérard. La théorie des champs conceptuels. Recherches em Didactiques des Mathématiques, 10 (23), p. 133-170, 1990. 